\title{
Questes
}

vestes Revue pluridisciplinaire d'études médiévales

$36 \mid 2017$

Faire de l'histoire au Moyen Âge

\section{Faire de l'histoire : avant-propos}

\section{Franck Collard}

\section{(2) OpenEdition}

\section{Journals}

\section{Édition électronique}

URL : http://journals.openedition.org/questes/4423

DOI : 10.4000/questes.4423

ISSN : 2109-9472

\section{Éditeur}

Les Amis de Questes

\section{Édition imprimée}

Date de publication : 20 juin 2017

Pagination : 1-2

ISSN : 2102-7188

\section{Référence électronique}

Franck Collard, «Faire de l'histoire : avant-propos », Questes [En ligne], 36 | 2017, mis en ligne le 02 juillet 2017, consulté le 25 septembre 2020. URL : http://journals.openedition.org/questes/4423 ; DOI : https://doi.org/10.4000/questes.4423 


\section{Avant-propos}

\section{Franck COLLARD}

Université Paris-Nanterre

Devant se mettre en quête d'un représentant de la génération précédant la leur pour servir de préfacier à une livraison sur l'écriture de l'histoire, les jeunes historiens maîtres d'œuvre de l'entreprise Questes n'ont assurément pas choisi le spécialiste le plus exemplaire de l'historiographie médiévale parce que, depuis ses travaux doctoraux consacrés, en 1994, à l'abrégé d'histoire de France en latin du décrétiste trinitaire Robert Gaguin (1495), leur interlocuteur a multiplié les infidélités à son sujet de recherche originel et perdu quelque peu le contact avec l'actualité scientifique et éditoriale de ce domaine toujours très actif de la médiévistique. La lecture des contributions ici réunies a donné l'occasion d'y revenir pour constater le dynamisme des enquêtes en cours, leur variété et la richesse des problématiques adoptées.

La sollicitation adressée au bien indigne préfacier - pour reprendre le motif de l'excusatio propter infirmitatem si présent dans les prologues aux chroniques médiévales - a néanmoins le mérite de souligner indirectement mais si légitimement l'importance et l'influence de l'œuvre matricielle d'un grand médiéviste disparu en 2010 et omniprésent dans chacun des textes ici présents: Bernard Guenée, directeur rigoureux de tant de thèses d'historiographie dans les années 1980-1990, maître révéré de celui qui parle et auteur d'une synthèse magistrale voici près de quarante ans sur l'histoire et la culture historique dans l'Occident médiéval. Il fut aussi un fin connaisseur d'auteurs aussi importants que 
Primat, Bernard Gui, Michel Pintouin, Froissart ou Thomas Basin, et l'inspirateur inépuisable de disciples nombreux, impressionnés et conquis par son art d'allier l'érudition et le bon sens, par son ampleur de vue et son goût du concret, par sa puissance interprétative et sa prudence systématique.

Sur ses pas exigeants ont cheminé ses élèves et les élèves de ses élèves y cheminent encore. Car s'il a ouvert de multiples pistes et découvert de multiples champs d'études, il n'a bien évidemment pas asséché cette source abondante de recherches qu'est la production historiographique des temps médiévaux. Les pages qui suivent en examinent quelques spécimens fort divers, de la chronique monastique du $\mathrm{XI}^{\mathrm{e}}$ siècle finissant aux fameuses Grandes chroniques de France, ce Roman aux Roys auquel Bernard Guenée a consacré, sans pouvoir le parachever, son ultime livre. Il ressort des travaux ici présents la confirmation et l'illustration de ses intuitions fécondes: diversité des profils d'auteurs souvent praticiens d'autres types de texte, porosité de frontières génériques finalement assez indifférentes aux esprits du temps, technicité des écritures de l'histoire, permanence des finalités mémorielles et idéologiques au profit d'une abbaye, d'un lignage ou d'un royaume, pluralité des usages des œuvres historiques lues à différents niveaux, adaptées, reconfigurées, bref vivantes bien après la mort de leur auteur, tout comme l'historiographie médiévale demeure bien vivante sept ans après le décès de son refondateur.

Faire l'histoire de l'histoire retient encore de nos jours de prometteurs jeunes esprits, capables de franchir allègrement les frontières disciplinaires, et c'est tant mieux, à l'heure où s'exacerbent les débats sur les conceptions de l'histoire. 